Mimetic Reflections 



\title{
MIMETIC REFLECTIONS
}

\author{
A Study in \\ Hermeneutics, Theology, and Ethics
}

\author{
by \\ WiLliam SCHWEIKER
}

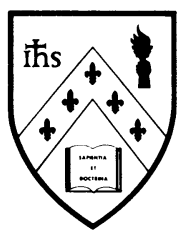

FORDHAM UNIVERSITY PRESS

NEW YORK 
(C) Copyright 1990 by FordHAM UNIVERSITY

ALL RIGHTS RESERVED

LC 89-85847

ISBN $0-8232-1253-X$ (clothbound)

ISBN 0-8232-1254-8 (paperback)

Printed in the United States of America

Third printing 1999

Schweiker, William.

Mimetic reflections: a study in hermeneutics, theology, and ethics.

ISBN: 0-8232-1254-8

1. Imitation. 2. Hermeneutics. 3. Theology. 4. Ethics. I. Title.

BH301.I55 S38 1995

190

LCCN: 89-85847 